\title{
8
}

\section{im

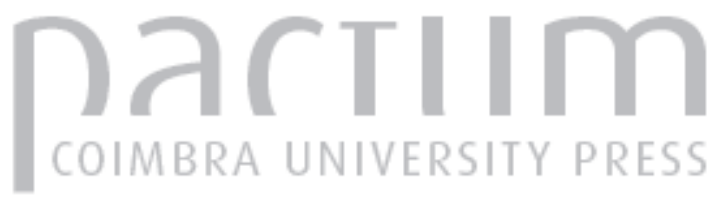

Otzi, a múmia glaciar e as suas sobrevidas: a personagem nas novas narrativas de ciência

Autor(es): $\quad$ Peixinho, Ana Teresa

Publicado por: Imprensa da Universidade de Coimbra

URL persistente:

URI:http://hdl.handle.net/10316.2/43605

DOI:

DOI:https://doi.org/10.14195/2183-6019_6_2

Accessed : $\quad$ 26-Apr-2023 14:06:53

A navegação consulta e descarregamento dos títulos inseridos nas Bibliotecas Digitais UC Digitalis, UC Pombalina e UC Impactum, pressupõem a aceitação plena e sem reservas dos Termos e Condições de Uso destas Bibliotecas Digitais, disponíveis em https://digitalis.uc.pt/pt-pt/termos.

Conforme exposto nos referidos Termos e Condições de Uso, o descarregamento de títulos de acesso restrito requer uma licença válida de autorização devendo o utilizador aceder ao(s) documento(s) a partir de um endereço de IP da instituição detentora da supramencionada licença.

Ao utilizador é apenas permitido o descarregamento para uso pessoal, pelo que o emprego do(s) título(s) descarregado(s) para outro fim, designadamente comercial, carece de autorização do respetivo autor ou editor da obra.

Na medida em que todas as obras da UC Digitalis se encontram protegidas pelo Código do Direito de Autor e Direitos Conexos e demais legislação aplicável, toda a cópia, parcial ou total, deste documento, nos casos em que é legalmente admitida, deverá conter ou fazer-se acompanhar por este aviso.

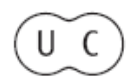


revista de comunicação,

jornalismo e espaço público

\section{6}

Periodicidade

Semestral

Imprensa da Universidade de Coimbra

Coimbra University Press

\section{mediapolis}

personagens mediáticas:

teoria, problemas, análises media characters:

theory, problems, analyses 
Ana Teresa Peixinho

CEIS20 / CLP

apeixinho71@gmail.com

ORCID: 0000-0002-4533-7921

\section{Otzi, a múmia glaciar e as suas sobrevidas:}

a personagem nas novas narrativas de ciência

Ötzi, the ice mummy and its afterlives: Character in the new science narratives

https://doi.org/10.14195/2183-6019_6_2

Resumo

Propõe-se, neste artigo, mostrar como a personagem é um elemento estruturante na comunicação narrativa, fundamental para a construção de laços com a instância da receção.

Dentro dos modelos teóricos sobre a categoria personagem, Ralph Schneider, adotando o modelo cognitivo e partindo do pressuposto da natureza dupla da personagem - ou seja, ela é simultaneamente baseada em pessoas "reais" e resulta de um processo compósito de construção concebe a personagem como um modelo mental que o leitor / espectador / ouvinte ativa com base em informações imanentes ao texto, combinando-as com a informação mental e cognição social (Schneider, 2001, p. 608).

Este modelo teórico parece, neste contexto, muito pertinente, pois poderá responder à hipótese de trabalho inicial: a saber, a de que a personagem é a categoria indispensável para a construção da sedução pela narrativa. A identificação gerada na instância recetora - a que alguns autores preferem chamar de empatia - passa necessariamente pelas emoções envolvidas no ato de receção.

Tomar-se-á como estudo de caso uma narrativa de rádio em podcast (http:// www.radiolab.org/story/ice-cold-case/) que constrói uma história à volta de um achado arqueológico - uma múmia glaciar da Idade do Bronze - com vista a transmitir conteúdos científicos a um público não especializado. Situamo-nos, portanto, no âmbito da comunicação de ciência, em que o storytelling (Dahlstrom, 2014) e, dentro dele, a figuração da personagem (Reis, 2015), são expedientes nucleares de sedução do público ouvinte e 'facilitadores' da comunicação.

Palavras-chave: personagem, narrativa de ciência, storytelling, rádio, polifonia

\section{Abstract}

This paper aims to show how character is a structuring element in narrative communication, being fundamental for establishing links with the receiver.

Within the theory of character, Ralph Schneider adopts the cognitive model and assumes the double nature of character as based on 'real' people and simultaneously resulting from a composite process of construction. He thus understands character as a mental model that the reader/ spectator/listener activates on the basis of data that are immanent in the text, combining it with mental information and social cognition (Schneider, 2001, p. 608). This theoretical model seems to be very pertinent in this context since it may provide an answer to the initial working hypothesis, i.e., that character is indispensable for the narrative construction of seduction. The identification that it generates in the receiver - called empathy by some authors - necessarily engages the emotions that emerge in the act of reception.

As a case study, we will focus on a radio podcast narrative (http://www.radiolab. org/story/ice-cold-case/) that builds a story around the archaeological finding of a wet mummy from the Bronze Age with the goal of conveying scientific content to nonexpert audiences. We are, therefore, in the realm of science communication, in which storytelling (Dahlstrom, 2014) and the figuration of character (Reis, 2015) are crucial means to seduce the audience and to facilitate communication.

Keywords: character, science narrative, storytelling, radio, polyphony 


\section{Introdução}

Na senda de uma tendência dos atuais Estudos Narrativos, pretende-se, neste artigo, sustentar a centralidade da personagem como elemento estruturante da comunicação narrativa, fundamental para a construção de relações empáticas com o recetor (leitor, espectador ou ouvinte) ${ }^{1}$. Ilustra-se esta abordagem através de um estudo de caso sobre uma narrativa radiofónica, com o objetivo de transmitir conteúdos científicos a um público não especializado, construída a partir de uma descoberta arqueológica. A comunicação de ciência será o nosso âmbito epistemológico, na qual o storytelling e, dentro dele, a figuração da personagem, são expedientes nucleares de promoção da eficácia comunicativa através da sedução do público ouvinte.

Parece ser redundante traçar aqui a evolução do estudo da categoria personagem na diacronia dos estudos da e sobre narrativa, até porque tal foi já circunstanciadamente explicado e

1 Doravante, utilizar-se-á o termo leitor em latu sensu, englobando recetores de diversos media e linguagens (leitores, ouvintes, espectadores, usuários). descrito por diversos investigadores (Heidbrink, 2010; Janidis, 2013; Reis, 2013; 2015; Scnheider, 2001). Todavia, afigura-se importante sublinhar, nesse longo caminho que remonta a Aristóteles e Horácioº ${ }^{2}$ alguns momentos charneira: i) a abordagem de herança formalista de Vladimir Propp, desenvolvida no clássico Morfologia do Conto cuja primeira edição data de 1957; ii) na senda deste, a tipologia funcionalista de Greimas que teve o mérito de afastar a análise da personagem do domínio subjetivo do psicologismo (Greimas, 1983) ${ }^{3}$; iii) a abordagem de Seymour Chatman que, embora ainda de matriz estruturalista, inaugura o debate em torno da personagem numa perspetiva de receção, antecipando alguns desafios

2 Que a problemática da 'personagem' remonta à 'pré-história' dos Estudos Narrativos provam-no a abordagem de Aristóteles na sua Poética, distinguindo a construção do herói na tragédia e na comédia, ou o argumento de Horácio na Arte Poética que prevê a necessária coerência entre o conteúdo e o estilo na construção de personagens.

3 Carlos Reis sintetiza-o bem: "o projeto estruturalista era de índole translinguística e o seu aprofundamento semiótico, na abordagem greimasiana, acentuou a dimensão funcionalista dos agentes narrativos, reduzidos à condição abstrata de papéis actanciais sem densidade humana" (Reis, 2013, s.p.). posteriores, iv) superados pelas teorias cognitivistas que começaram a desenvolver-se na década de 90 e que têm o mérito de investir em abordagens interdisciplinares, afastando-se do restritivo paradigma estruturalista (Margolin, 2005; Heidbrink, 2010; Jannidis, 2013; Schneider, 2001).

Sabe-se hoje o quanto os Estudos Narrativos, sobretudo nos últimos anos, têm insistido nas abordagens cognitivistas: autores de referência como Jens Edder ou Fotis Jannidis têm dedicado parte das suas investigações precisamente à valorização da vertente recetiva na compreensão do funcionamento de algumas categorias narrativas, nomeadamente da personagem, cuja identidade deve ser entendida como uma relação comunicacional, e cuja coerência decorre da interação do leitor com o material mediático (Heidbrink, 2010). De acordo com Fotis Jannidis,

Until recently, there was nothing like a coherent field of research for the concept of character, but only a loose set of notions related to it touching on such issues as the ontological status of characters, the kind of knowledge necessary 
to understand characters, the relation between character and action, the naming of characters, characterization as process and result, the relation of the reader to a character centering around the notions of identification and empathy, etc. (Jannidis, 2013).

No processo de alargamento epistemológico que conheceram os Estudos Narrativos desde o final da década de 90 do século passado, a personagem é uma das categorias mais favorecidas, em virtude de um conjunto de estudos, na esteira de Uri Margolin, responsáveis pela ressurreição da categoria que "nenhuma narrativa dispensa". De facto, nos últimos quinze anos, estudos monográficos sobre personagem, sobretudo influenciados pela matriz cognitivista, trouxeram novas luzes sobre esta categoria narrativa, o que tornou possível o consenso sobre alguns aspetos do funcionamento da personagem e a abertura a novas formas de leitura e apropriação.

Partindo do princípio de que a complexidade do conceito não facilita uma definição unívoca, uma vez que esta dependerá sempre do modelo
No processo de

alargamento

epistemológico

que conheceram os

Estudos Narrativos

desde o final da

década de 90 do

século passado, a

personagem é uma

das categorias

mais favorecidas. teórico e da perspetiva ${ }^{4}$, há, porém, um aspeto que parece reunir alguns consensos: i) a personagem é sempre uma construção ii) cuja substância de expressão é material semiótico seja verbal, não verbal ou ambos em simultâneo iii) e é sempre veiculada por um medium.

A abordagem que hoje se propõe - ancorada num estudo de caso - integra-se precisamente num contexto de abertura da narratologia a outras áreas de estudo ${ }^{5}$, nomeadamente às Ciências

4 Dentro dos modelos teóricos sobre personagem, nomeadamente nos modelos de natureza representacional - que entendem a personagem como ser e não apenas como unidade lexical, temática e compositiva da narrativa - esta pode ser lida sob três perspetivas: i) como unidade textual aberta, mantendo sempre pontos de indeterminação, a personagem existe no mundo possível criado pelo texto, estabelecendo com a pessoa uma relação escalar, entre a maior ou menor verosimilhança; ii) como unidade virtual, construída pelo recetor com base em modelos mentais, socialmente partilhados e textualmente construídos; iii) como unidade comunicativa (Herman, 2002).

5 Cruzando-se com outras áreas de estudo e autonomizando-se em relação à Literatura e à matriz linguístico-semiótica, os estudos narrativos são hoje um campo em ascensão, conjugando-se "com as solicitações e com os fundamentos epistemológicos da retórica, das ciências cognitivas, dos estudos feministas, dos estudos culturais ou dos estudos mediáticos" (Reis, 2013). 
da Comunicação (onde se integra a comunicação de ciência), aos Media Studies (que fornecem os conceitos e os instrumentos metodológicos para a análise de uma narrativa de rádio) e aos Estudos Cognitivos (que permitem compreender os mecanismos de identificação e perceção).

\section{Comunicação de ciência e storytelling}

Pretende-se compreender e analisar a construção de uma narrativa de um programa de rádio americano sobre uma descoberta arqueológica na Europa: a de um corpo mumificado, com mais de 5000 anos, acidentalmente encontrado por dois turistas num vale glaciar do Sul do Tirol, entre a Itália e a Áustria. Trata-se de uma história áudio do "Radiolab", programa produzido pela estação pública New York Public Radio (WNYC) ${ }^{6}$ e transmitido para mais de 500 estações nos EUA, sendo posteriormente disponibilizado

6 Estação lançada em 1924, que funcionou, até ao fim da década de 90, como a rádio de Nova Iorque, adquirindo, em 1997, um alcance nacional (dados mais circunstanciados sobre a história desta estação em www. nypublicradio.org/about/). em podcast, habitualmente em dois formatos: os programas longos, de cerca de uma hora, e os episódios designados de Radiolab Shorts, onde esta narrativa, com cerca de 20 minutos, se inclui.

Vale a pena ler o enunciado de apresentação pública do programa "Radiolab", pois ele contém alguns elementos que serão úteis à leitura que aqui se propõe. No seu site, lê-se: "Radiolab is a show about curiosity. Where sound illuminates ideas, and the boundaries blur between science, philosophy, and human experience" (http://www.radiolab.org/).

Em primeiro lugar, assume-se, nesta apresentação, que se trata de um show: não é informação, não é jornalismo, não é discurso científico. Embora a palavra show possa ser geralmente traduzida por "programa', "Radiolab" é um verdadeiro entretenimento com dois «hosts», dois anfitriões, como se de um espetáculo de palco se tratasse. Aliás, por vezes, "Radiolab" sai do estúdio, faz digressões pelos diferentes Estados e tem apresentações em salas com público ${ }^{7}$ No final do

\footnotetext{
7 Veja-se o modo como é apresentado em digressão pelos EUA: http://www.radiolab. org/story/300293-tickets-sale-now-our-new-
}

episódio ${ }^{8}$ que neste texto se analisa, o produtor faz, inclusive, referência às apresentações ao vivo que estariam a decorrer em digressão.

Em segundo lugar, é importante que, no enunciado de apresentação do projeto, se insista na "curiosidade" - Radiolab é um "show sobre curiosidade" - o que aponta claramente para uma particular atenção dada à gestão da atenção do ouvinte. Trata-se de construir histórias orais, mediadas pela rádio (tradicional e digital) - cujo material significante é a voz, a música, os efeitos sonoros, os silêncios -, com vista a promover a imersão dos ouvintes em universos diegéticos tematicamente híbridos que cruzam ciência, filosofia, estética, conhecimento humano - e em que as fronteiras entre factual e ficcional se esbatem: se, por um lado, as histórias aqui criadas partem de factos cientificamente comprovados e de temas estudados (no caso em apreço, como se verá, a descoberta de um corpo

-live-show/ (consultado a 23 de junho de 2017).

8 Para ouvir o programa: http://www.radiolab.org/story/ice-cold-case/ (consultado em junho de 2017). 
mumificado com 5300 anos), as narrativas produzidas transcendem essa factualidade, descolam do discurso científico tradicional e são construídas com recursos característicos da ficção narrativa.

Apesar de o programa não se definir como jornalístico, ele possui, não obstante, essa matriz muito vincada: com frequência, o que "Radiolab" faz é jornalismo de investigação de grande qualidade, rigoroso e caucionado por fontes credíveis. A linha do episódio que aqui se analisará, em que a investigação científica - e simultaneamente jornalística - serve de base a uma reconstituição, é denominador comum a muitos episódios produzidos por "Radiolab".

No âmbito da comunicação de ciência, parece ser relativamente consensual que a estratégia do storytelling tem sido recorrente nos últimos anos $^{9}$, sobretudo desde o advento da

9 A principal ideia de força defendida por Bryan Alexander (2011) é precisamente a de que os novos meios digitais permitem incrementar formas e lógicas narrativas novas, tornando as histórias mais criativas e disseminadas. É precisamente o digital que proporciona, segundo o autor, novas formas de contar histórias, renovando as narrativas e tornando-as mais próximas do perfil, das
WEB 2.0, em que novas linguagens, plataformas e novos media abriram caminhos a novas narrativas que, comparativamente ao discurso ensaístico ou argumentativo tradicional, apresentam diversas vantagens comunicacionais (Avraamidou e Osborne, 2009; Dalshtrom, 2014) ${ }^{10}$.

Não se aprofundarão por ora as controversas questões éticas impli$\operatorname{cadas}^{11}$ no recurso a este expediente, mas sublinha-se um aspeto que a literatura mais recente sobre o tema

exigências e apetências dos públicos do século XXI.

10 Lucy Avraamidou e Jonathan Osborne sistematizam os quatro principais formatos dos textos de comunicação de ciência - expositivo, argumentativo, narrativo e misto (narrativo e expositivo) -, comentando de modo sumário as suas potencialidades. Sobre o modo narrativo explicam: "Such text is commonly used by popularisers of science for the purpose of stimulating the interest and holding the attention of the reader" (Avraamidou e Osborne, 2009: 1690).

11 Esta é uma problemática delicada no âmbito da comunicação de ciência, nomeadamente no que diz respeito à estratégia do storytelling: qual o propósito do recurso à narrativa - persuadir ou fomentar a compreensão? Como se define o nível de correção e rigor, valores inalienáveis do discurso de ciência? Michael Dalhstrom, embora não apresente respostas conclusivas, coloca estas questões na abordagem à narrativa como estratégia de comunicação de ciência (Dalhstrom, 2014). tem retomado: através da narrativa, promove-se o nível de persuasão da informação, porque se melhora a compreensão por meio de exemplos vívidos e porque se envolve o recetor num universo construído que ele perceciona como um mundo possível:

This reliance on narratives is suggested to be the result of an evolutionary benefit because narratives provide their users with a format of comprehension to simulate possible realities, which would serve to better predict cause-and-effect relationships and model the thoughts of other humans in the complex social interactions that define species" (Dalshtrom, 2014, s.p.).

As narrativas conseguem captar melhor a atenção dos leitores: porque partilham socialmente os sentidos; porque desencadeiam um processo cognitivo que convida o recetor a imergir no universo diegético; porque envolvem processos emocionais. Construir histórias que veiculem conhecimentos de teor científico facilita a assimilação dos conceitos, nos vários contextos relacionados com 
comunicação de ciência, sejam eles pedagógicos, de divulgação ou jornalísticos.

Por outras palavras, numa perspetiva cognitivista, a narrativa é um modelo de comunicação mais eficaz porque mais persuasivo, o que decorre do seu estatuto privilegiado na cognição humana: "Our tendency to see and explain the world in common narratives is so deeply ingrained that we often don't notice it - even when we've written the words ourselves", comenta Daniel Pink (2006, p. 106). Umbilicalmente ligada ao conhecimento, desde logo por um vínculo etimológico, a narrativa é o modo discursivo e o tipo textual através do qual se organiza o mundo, se criam imagens do real, se articula e se lê a sua complexidade, produzindo crenças sociais, ditando normas de conduta, disseminando estereótipos e fornecendo imagens dos outros. Em consonância com alguns autores, o mundo a que se acede maioritariamente mediatizado - constrói-se necessariamente de acordo com certos princípios narrativos, pois o pensamento, as estruturas mentais e conhecimento processam-se por meio da narrativa:

\begin{abstract}
Actions, intentions and feelings are all part of the human experience, which is reported and, at the same time, evaluated in narratives. (...) Experienti- ality is itered through consciousness, thus implying that narrative is a subjective representation through the medium of consciousness (Fludernik, 2006, p. 109).
\end{abstract}

Stephen Norris (2005), procurando entender os efeitos da narrativa na comunicação de ciência, considera existirem oito componentes fundamentais da narratividade que explicam a supremacia deste recurso na memorização, na compreensão e na interpretação do mundo: eventos, narrador, 'apetite' narrativo, tempo, estrutura, agentes, propósito e leitor. Percebe-se que esta sistematização descreve hierarquicamente algumas das categorias narrativas - ação, tempo e personagem - e contempla os dois polos da comunicação narrativa - narrador e (narratário) leitor e respetivas estratégias em termos de construção da comunicação narrativa. A leitura de Lucy Avraamidou e Jonathan Osborne (2009), compaginando-se com a de Norris, sublinha a importância da personagem como elo fundamental ao leitor e meio de construção do 'apetite narrativo'. Acrescentam estes autores, ainda, alguns exemplos de trabalhos empíricos, que têm sido desenvolvidos nas duas últimas décadas neste domínio, e cuja análise demonstra as vantagens do recurso à narrativa na comunicação de ciência: maior compreensão sobre assuntos de ciência; aumento das competências interpretativas; enriquecimento dos modelos cognitivos; alterações nas vivências e nas visões sobre ciência, realidade e vida (Avraamidou e Osborne, 2009, pp. 1697-1698).

Trata-se, no caso que aqui se apresenta, de um áudio com cerca de 20 minutos, gravado em estúdio, que conta com a presença de um botânico - Jim Dickson -; do Diretor do Instituto para Múmias e Homens do Gelo - Albert Zinc -; de um artista gráfico - Aaron Birk -; do produtor ${ }^{12}$ Andy Mills e dos dois apresentadores - Robert e Jad. Dos diálogos entre estes intervenientes, tece-se uma narrativa

\footnotetext{
12 A expressão é usada no contexto anglo-saxónico: é quem, na verdade, faz a peça.
} 


\section{Por meio de uma}

cujo desenvolvimento, evolução, sintaxe e dinâmica se processam através da construção de uma personagem: a partir de uma múmia encontrada inadvertidamente no Tirol por dois caminhantes em 1991, constrói-se uma narrativa a várias vozes - polifónica - que tenta figurar o achado arqueológico, humanizando-o, dando-lhe um rosto, um corpo, reconstruindo a sua vida, atribuindo-lhe uma identidade e um nome - Otzi. Por meio de uma história contada, transmite-se um conteúdo científico específico, carreando os saberes da arqueologia, das ciências forenses, da botânica, da antropologia, da bioquímica, através de discursos correntes, facilmente assimiláveis e acessíveis a um público mais alargado.

A narrativa é construída com o recurso a três expedientes: i) polifonia, ii) jogo de efeitos sonoros e iii) a centralidade da personagem. Vejamos como se constrói esse expediente polifónico e quais os seus efeitos. Uma vez que cada um dos seis participantes no programa vai acrescentando dados novos à história, não existe a linearidade de uma voz narradora única e hegemónica, que oferece a história como um todo com princípio, meio e fim. Ao história contada,

transmite-se

um conterido

científico específico,

carreando os

saberes da

arqueologia, das

ciências forenses,

da botânica, da

antropologia,

da bioquímica,

através de

discursos correntes,

facilmente

assimiláveis e

acessíveis. contrário, a intervenção de cada participante em estúdio vai acrescentando dados, informações, fragmentos que ligam a malha narrativa, corporizando a personagem e construindo a diegese, num efeito de ausência de mediação improvisada, similar a uma narrativa conversacional, em que se contam histórias: todas as vozes contribuem para a progressão da diegese.

Segundo David Herman, o storytelling conversacional é um processo interativo, que pode ser protótipo de toda a narração, basicamente fundado numa negociação permanente entre contadores e ouvintes (Herman, 1999). E essa transposição entre a fluência aparentemente improvisada da conversa entre os especialistas em estúdio e a história é da responsabilidade de Andy, o produtor. Embora Robert e Jad, os anfitriões, abram o programa, apresentando os convivas e o "espetáculo", decorridos três minutos, passam a palavra ao produtor que, a partir desse momento, assume o papel do narrador / contador, começando a história pelo seu início - a descoberta inesperada de um corpo no ano de 1991. Os anfitriões Robert e Jad - passam a desempenhar a função de gancho narrativo, fazendo 
as perguntas que o ouvinte gostaria de ver respondidas e cuja resposta contribui para a progressão da história. Não contribuindo diretamente para o avanço da narrativa - que se vai processando pela voz de Andy e pelas intervenções dos convidados em estúdio - os dois anfitriões são peças-chave para a construção da expectativa e do suspense. Colocando-se na pele do público, vão perguntando: quão velho é ele? Qual a sua aparência? Meias de relva, o que são meias de relva? Foi assassinado? Como se percebe pelo teor de algumas das questões selecionadas, elas dizem exclusivamente respeito ao protagonista Otzi, cuja identidade vai sendo figurada através de uma espécie de jogo entre os indícios dados pelas intervenções dos convivas, a expectativa dos ouvintes, os efeitos sonoros e musicais e as perguntas de Robert e Jad.

Assim, durante a peça, entre os 3 minutos e os 20 minutos do programa, os dois anfitriões não introduzem qualquer facto ou ação: perguntam e, muito esporadicamente, deixam escapar expressões de assentimento ou espanto; dramatizam as possíveis reações dos ouvintes e investem no suspense narrativo, adensando a aura de mistério
Tratando-se de uma narrativa radiofónica, os efeitos sonoros

são igualmente

fundamentais para

essa estratégia: a

música, os sons,

as vocalizações, os

silêncios contribuem

para a construção

do enigma, que se

vai desvendando

progressivamente,

como se de um

episódio da famosa

série CSI se tratasse. que se cria em torno da personagem descoberta. Tratando-se de uma narrativa radiofónica, os efeitos sonoros são igualmente fundamentais para essa estratégia: a música, os sons, as vocalizações, os silêncios contribuem para a construção do enigma, que se vai desvendando progressivamente, como se de um episódio da famosa série CSI se tratasse. Embora o som, como substância semiótica, não partilhe a convencionalidade do signo verbal ou a iconicidade das imagens, ele contribui decididamente para a construção de ambientes e para a sugestão de impressões junto do público:

As the focus of interest of a schoraly approach, the narrativity of music is a purely analytical construct situated, cognitively, on a very diferente level than the narrativity of language, film, or even pictures because it can exercise its power without being consciously recognized (Ryan, 2014, s.p.).

\section{Otzi: personagem e empatia}

A narrativa que aqui se analisa centra-se, de facto, na construção de 
uma figura: desde o seu aparecimento como um "corpo" descoberto em 1991 por dois caminhantes alemães, até ao momento em que ganha um nome 'Otzi' e uma humanidade, simbolicamente representada pela cena final: a da última refeição à beira do fogo.

Parece ser relativamente consensual que a personagem, em contexto ficcional, é uma construção criativa, tendencialmente humanizada, que possibilita a representação de seres originais, autênticos e individuais (Heidnrink, 2010). A aceitação destas premissas decorre sobretudo da evolução que o estudo da personagem começou a conhecer a partir do fim do século passado, em que é resgatada, como já se disse, do espartilho a que a narratologia estruturalista a havia condenado.

Ralph Schneider, adotando o modelo cognitivo e partindo do pressuposto da natureza dupla da personagem - ou seja, ela é simultaneamente baseada em pessoas "reais" e resulta de um processo de construção - concebe a personagem como um modelo mental que o recetor ativa com base em informações imanentes ao texto, combinando-as com a informação mental e cognição social (Schneider, 2001, p. 608). Este modelo teórico parece ser, neste contexto, muito pertinente, pois talvez consiga responder à hipótese de trabalho inicial: a de que a personagem é categoria indispensável para a construção da empatia narrativa. A identificação gerada no leitor - a que alguns autores preferem precisamente dar o nome de empatia $^{13}$ - passa necessariamente pelas emoções envolvidas na receção à personagem. É por ela que o leitor reage ao mundo narrativo, se deixa imergir, infere, antecipa e projeta sentidos, etc.

Ouvindo com alguma atenção o podcast, consegue perceber-se que a figura do protagonista Otzi vai sendo sujeita a um progressivo processo de figuração, que tem início no seu aparecimento na narrativa - a descoberta de um corpo em 1991 no Tirol - até ao momento final em que é personagem /

13 As emoções também desempenham um papel na receção da personagem. A empatia, termo utilizado por Zillman e que Ralf Schneider prefere ao de identificação, resulta da capacidade de o leitor reagir à personagem, podendo imaginar a situação, o seu desfecho, antecipando o que ela significa (Schneider, 2001: pp. 613 e ss). pessoa $^{14}$, com direito a nome próprio e a uma substância corpórea e anímica.

A construção desta figura é fundamentalmente feita com o recurso a dois expedientes: i) pistas e indícios científicos - lidos e interpretados por um conjunto de saberes, desde a antropologia às ciências forenses, pelas vozes dos diferentes convidados do programa; ii) mas também pelas inferências diegéticas que os dois anfitriões vão fazendo, e que envolvem a personagem numa aura de humanidade. A dado momento, deixa de ser o corpo mumificado encontrado no vale glaciar - na condição de objeto de atenção, de objeto de estudo, de objeto de ciência - para passar a ter um nome, uma identidade, ações, sentimentos e sensações. A própria locução o refere no final, quando descreve o sofrimento, a fome, o frio,

14 Como explica H. Heidbrink, este binómio pessoa/personagem foi foco de um prolongado debate entre posições humanísticas que encaravam a personagem numa base fenomenológica e hermenêutica - e posições formalistas - que a liam como mera função textual sem autonomia para além do material semiótico que a compunha. Esta dicotomia reflete-se nos binómios homo sapiens / homo fictus de Forster; persona / personagem de Iuri Lotman (Heidbrink, 2010, pp. 72 e ss). 
a tenacidade face às tormentas que Otzi terá experienciado horas antes da morte, assim lhe conferindo a "sense of humanity".

Ora este 'sentido de humanidade', que remete para uma conceção antropomórfica da figura em causa, é aqui claramente construído abdutivamente, através de inferências, que inscrevem a figura num mundo possível de vida, e para as quais contribui o jogo sonoro e musical com tonalidades diversas que imprimem à diegese a aura de mistério, de sentido temporal, de vivacidade, de ação, de contemplação e até de humor.

No fundo, através da história de Otzi, da reconstituição do seu passado, dos seus percursos, da sua indumentária, o ouvinte acede a um conjunto de conteúdos científicos que, transmitidos de outro modo, certamente teriam um impacto diferente. As intervenções de cariz científico dos especialistas convidados - recorde-se um botânico, um antropólogo, um artista gráfico que explicam, por exemplo, os contributos da botânica e da climatologia na análise e interpretação do conteúdo do estômago da múmia, o que terá permitido reconstituir o seu percurso nas últimas horas de vida - contribuem para a história da personagem e para a sua figuração. Trata-se de dados e factos científicos ao serviço da diegese e da construção do perfil da personagem. Porém, esta muito deve também à imaginação interpretativa do ouvinte, sempre incentivada e alimentada pelos comentários, perguntas e interjeições dos dois jornalistas anfitriões.

Ao processo de humanização da personagem não são alheios também duas outras estratégias articuladas: um procedimento metaléptico e a migração da personagem para outras narrativas, consubstanciando aquilo a que Carlos Reis chama de sobrevi$\mathrm{da}^{15}$. Otzi, nome dado pela comunidade científica ao mais antigo fóssil humano integral alguma vez encontrado, é quase uma celebridade ${ }^{16}$, tendo

15 "Conceito que remete para um fenómeno de metalepse e/ou refiguração de uma personagem que, através da transposição mediática, ganha uma nova existência, à margem da diegese. Recorrendo à trilogia mimética de Paul Ricoeur, na mimese I, a personagem é pré-figurada, na segunda, ganha existência textual e, por fim, ocorre a refiguração, isto é, a personagem, através da recriação, ganha uma outra existência, em suma, uma sobrevida" (Perpétua, 2017, p. 1).

16 Por exemplo, a estrela de cinema Brad Pitt tem a tatuagem de Otzi no seu braço dado origem a múltiplas narrativas em suportes mediáticos diversos: um site, livros, narrativas de comunicação de ciência, como a que analisamos, e, a partir dela, até a uma narrativa ficcional. Referimo-nos a um conto, «The Iceman Speaks» ${ }^{17}$, da autoria do jovem escritor norte-americano Stefan Merrill Block ${ }^{18}$, aficionado da Radiolab, em que Otzi, narrador autodiegético, acorda no laboratório para onde o haviam levado os cientistas e olha o mundo atual, cinco mil e trezentos anos depois. Ou seja, de múmia encontrada no vale glaciar, a personagem de história ficcional, é indiscutível que Otzi adquiriu pelas narrativas que o foram figurando uma sobrevida que transcende claramente a narrativa científica inicial, na qual era apenas um fóssil humano.

Estes procedimentos de refiguração são acompanhados por saltos

esquerdo, junto com uma citação de Friedrich Nietsche "absurdities of existence" (http:// www.celebritytattoodesign.com/brad-pitt-tattoos) (consultado em junho de 2017).

17 Veja-se transcrição do conto em: http:// www.radiolab.org/story/iceman-speaks/ transcript/ (consultado em junho de 2017).

18 http://www.stefanmerrillblock.com/bio.html (consultado em junho de 2017) 
metalépticos que dão dinamismo à representação. A metalepse é um conceito oriundo da retórica, mas explorado e adaptado à análise narrativa por Gérard Genette (Genette, 2004):

It is important to bear in mind that although metalepsis has its roots in ancient rhetoric, narrative metalepsis is a recent concept in the history of poetics, with the practice itself, under different denominations, or none at all, reachinh back to antiquity in both literary and visual forms (Pier, 2014, s.p.)

Consiste em uma transgressão deliberada entre dois universos: o da narração e o da narrativa. Um dos autores responsáveis pela exportação do conceito para outros media que não a literatura, com particular enfoque em narrativas multimédia, foi Werner Wolf, para quem a metalepse é "uma transgressão intencional e paradoxal entre mundos ontologicamente distintos e níveis representados em mundos possíveis" (Wolf, 2005, p. 91). A permeabilidade entre níveis e mundos - o da ficção e o da realidade - pode ser suscitada quer do ponto de vista do produtor da narrativa, quer do ponto de vista do leitor/espectador e pode ter efeitos diversificados: "The former, both as production (author's metalepsis) and as reception (reader immersion), tends toward aesthetic illusion whereas the latter (...) postulates a higher and purely fictitious reality (Pier, 2014, s.p.).

Neste caso - a figuração de Otzi o processo metaléptico é conseguido sobretudo do lado da receção, já que a construção, composição e modelação da personagem exigem uma atitude ativa e colaborativa do ouvinte, nomeadamente a sua capacidade para, a partir do material sonoro, ir visualizando a personagem e para ir combinando os indícios e as pistas deixadas pela conversa em estúdio num todo diegético coerente.

\section{Conclusão}

A história radiofónica de Otzi produzida por Radiolab é um exemplo paradigmático de uma narrativa de ciência inovadora em rádio, que explora múltiplas linguagens, estratégias polifónicas e que rompe com o modelo sequencial da narrativa tradicional. Nela claramente a personagem é a categoria que permite a imersão do ouvinte, instigando-o a imergir na história e permitindo a construção de sentidos que claramente transcendem a simples divulgação de ciência.

Como elementos diferenciadores, encontram-se essencialmente três expedientes narrativos: i) a conjugação de procedimentos típicos de uma narrativa conversacional com expedientes ligados à narrativa multimédia; ii) a indefinição / transgressão de fronteiras consubstanciada no hibridismo genológico; iii) a subversão da linearidade emocional típica da narrativa de ciência. Na verdade, como a leitura precedente demonstrou, os dois jornalistas anfitriões - Robert e Jad - abandonando o papel de pivots a quem competia conduzir o programa, assumem as atitudes expectáveis de um ouvinte in loco, antecipando as reações, dúvidas, crenças e expectativas do público. Esta mutação de papéis é uma estratégia relevante para captar a atenção dos ouvintes, levando-os a sentirem-se, eles mesmos, em estúdio. Assim, a situação comunicativa mediática - que à partida pressupõe a reconstrução do quadro enunciativo em virtude da defetividade de uma comunicação a 
distância - é aparentemente transfigurada numa comunicação presencial, como se de uma história tradicional se tratasse. Para tal contribui o processo de dramatização, no qual a expressão pessoal dos dois jornalistas surge no mesmo patamar de uma factualidade mais característica quer da narrativa jornalística quer da narrativa científica. O produto final é uma narrativa plural e híbrida, em que se utilizam estratégias típicas de roteiro ficcional, na qual a personagem é exposta a situações limite, deixando o ouvinte em suspenso, gerindo as suas expectativas e mantendo a sua atenção.

Nos últimos cinco anos, tem-se assistido a um interesse crescente pelos podcasts, sobretudo aqueles que trazem histórias do quotidiano, de pessoas e sobre pessoas, que poderíamos arrumar sob o rótulo de human interest stories. O Radiolab é um dos melhores exemplos disso. Há, porém, outros, como o Serial, o This American Life ou, de forma mais organizada, o Radiotopia. Todos se propõem como alternativas à rádio mais frenética do drive time, apostando em narrativas que, embora recorrendo a media tecnologicamente avançados, recuperam o antigo prazer de contar e ouvir contar boas histórias.

\section{REFERÊNCIAS BIBLIOGRÁFICAS}

ALEXANDER, B. (2011). The New Digital Storytelling. Creating Narratives with New Media. Oxford: Praeger.

AVRAAMIDOU, L.; OSBORNE, J. (2009). The Role of Narrative in Communication Science. In International Journal of Science Education. N. ${ }^{\circ} 31$ (12), New York / London: Routledge, 1683- 1707.

GREIMAS, A. J. (1983). Du Sens II: essais sémiotiques. Éditions du Seuil: Paris.

DAHLSTROM, M. (2014). Using narratives and storytelling to communicate science with nonexpert audiences. In Proceedings of the National Academy of Sciences, 111 (Supplement 4), 13614-13620.

FLUDERNIK, M. (2006). An Introduction to Narratology. London / New York: Routledge.

HEIDBRINK, H. (2010), Fictional Characters in Literary and Media Studies. A survey of the Research. In J. Eder, F. Jannidis, R. Schneider (orgs.), Charaters in Fictional Worlds. Understanding Imaginary Beings in Literature, Film, and Other Media (pp. 67-110). Berlim / Nova Iorque: Walter De Gruyter. HERMAN, D. (1999). Toward a Socionarratology: New ways of Analizing Natural Language Narratives. In Herman, D. et al. (Eds.). Narratologies. New Perspectives on Narrative Analyses (pp. 218-246). Columbus: Ohio State UP.

HYVARINEN, M. (2010). Revisiting the Narrative Turns. In Life Writing, 7: 1, 69-82 (http://dx.doi. org/10.1080/14484520903342957 (Consultado em fevereiro de 2017). JANNIDIS, F. (2013). Character. In Hühn, Peter et al. (eds.). The living handbook of narratology. Hamburg: Hamburg University. http://www.lhn. uni-hamburg.de/article/character (Consultado em fevereiro de 2017)

JANNIDIS, F. (2003). Narratology and Narrative. In Kindt, T.; Muller, H. (Eds.). What is Narratology? (pp. 35-54).Berlin/NY: De Gruyter,

MARGOLIN, U. (1995). Characters in Literary Narrative: Representation and Signification. In Semiotica, N. ${ }^{\circ}$ 106, 373-392. 
MARGOLIN, U. (2005). Character. In Herman, D. et al. (Eds.). Routledge Encyclopedia of Narrative Theory (pp. 52-57) London: Routledge.

NORRIS, S. (2005). A Theoretical Framework for Narrative Explanation in Science. In Wiley Interscience (pp. 535-363) www.interscience.wiley. com (consultado em junho de 2017).

PERPÉTUA, M. (2017). Sobrevida (verbete para um Dicionário de Estudos Narrativos Mediáticos, produzido no âmbito do Seminário de Doutoramento de Estudos Narrativos Mediáticos, da Faculdade de Letras da UC).

PIER; J. (2014). Metalepsis. In Huhn, P. et al. (Eds.). The Living Handbook of Narratology. Hamburg: Hamburg University http://www.lhn.uni-hamburg.de/article/metalepsis-revised-version-uploaded-12-may-2014\#Genette72 (consultado em maio de 2016).

PINK, D. (2006). A Whole New Mind: Why Right-Brainers Will Rule the Future. New York: Riverheard.

REIS, C. (2015). Pessoas de Livro. Coimbra: IUC.

REIS, C. (2013). Morte e Ressurreição da Personagem. In https://figurasdaficcao. wordpress.com/2013/10/29/morte-e-ressurreicao-da-personagem/ (Consultado a 27 de fevereiro de 2017)

RYAN, M.-L. (2014). Narrative in various media. In: The Living Handbook of Narratology. Hamburg: Hamburg University http://www.lhn.uni-hamburg.de/article/narration-various-media (Consultado em julho de 2017).

SCNHEIDER, R. (2001). Toward a cognitive theory of literary character: the Dynamics of mental-model construction. In: Style, Vol. 35, N. ${ }^{\circ} 4,607-639$.

WOLF, W. (2005). Metalepsis as a transgeneric and transmedial phenomenon: a case study of the possibilities of 'exporting' narratological concepts. In MEISTER, J. C. (ed.). Narratology beyond literary critiscism: mediality, disciplinarity (pp. 83-107). Berlin: Walter de Gruyter. 